\title{
IX. On the existence of chemical compounds of short-lived radioactive elements
}

\section{Hans Schrader Ph.D.}

To cite this article: Hans Schrader Ph.D. (1912) IX. On the existence of chemical compounds of short-lived radioactive elements, Philosophical Magazine Series 6, 24:139, 125-134, DOI: 10.1080/14786440708637314

To link to this article: http://dx.doi.org/10.1080/14786440708637314

曲 Published online: 20 Apr 2009.

Submit your article to this journal $\sqsubset \pi$

Џll Article views: 4

Q View related articles $\square$

4 Citing articles: 2 View citing articles ๘ 
so that the velocity observed is only an average, and is less than the velocity would be if they were charged ali the time.

In conclusion, it may be said that the results obtained on the ionic velocities, coefficients of diffusion and conductivities of salt vapours in flames, seem to agree with the view that the positive ions consist of metal atoms having charges about three times the charge on one hydrogen ion in solutions. At the same time it must be pointed out that the possible error in the determinations of all these quantities is large; so that it is possible, but I think improbable, that the charge per ion is in reality equal to that on one hydrogen ion.

In a previous paper I gave reasons for believing that the positive ions due to salt vapours in flames are atoms of the metal. The arguments used in that paper are independent of the value of the charge carried by each ion so long as all the atoms when ionized carry the same charge. It has been suggested by Langevin that these ions are hydrogen atoms. 'This suggestion depends entirely on calculations of the ionic velocity by means of the formula $k=e \lambda / m v$. This formula cannot be relied on to give the velocity within a factor of at least two or three, partly owing to our ignorance of the true values of $\lambda$ and partly because the formula itself is unreliable. No suggestion has been made as to how hydrogen ions are produced by salt vapours; and moreover the experiments made to determine the ionic velocities cannot be explained satisfactorily on the view that the ions are hydrogen atoms. Also salt vapours produce enormous condnctivity in flames which contain no hydrogen. The increases of current observed in the determinations of the ionic velocities are nearly proportional to the conductivities due to the salt vapours, which shows that the ionic velocities measured are not those of a few special ions produced by some secondary reaction, but are the velocities of the majority of the ions due to the salts which must be formed from the salts, and therefore cannot be hydrogen.

IX. On the Existence of Chemical Compounds of Short-lived Radioactive Elements. By Hass Schnadre, Ph. $D$.* $^{*}$

Introduction.

THE short-lived radioactive transformation products of 1 radium, thorium, and actinium, which are included under the name of active deposits. do not differ fundamentally in their physical properties from the elements of

* Communicated by Prof. J. Rutherford, F.R.S. 
long life such as uranium, thorium, or radium. Their electrochemical properties are similar to those of the common metals*. They appear to be present in solutions as ions, and it would, therefore, seem probable that they are capable of forming chemical compounds in the same way as the long-lived products. If these compounds do exist, evidence of their presence can be obtained from a study of some of their physical properties, a method usually employed in differentiating between homogeneous bodies. In the present case, where bodies present only in extremely small quantities are under examination, recourse has been had to an investigation of their volatility and their solubility.

Makower $\dagger$ has made some experiments on this point, and found that radium $\mathrm{C}$, after being dissolved in hydrochloric acid and the solution evaporated to dryness, volatilized from surfaces of platinum and quartz in air at the same temperature as before such treatment. The result, therefore, indicates that, under the circumstances, radium $C$ had not been changed chemically in such a manner as to be more or less volatile.

\section{Volatilization of Active Material from Surfaces of Different Substances.}

The amount of an active body which can be volatilized at a fixed temperature depends on the nature of the surface on which it has been concentrated. Thus Makower found that only 85 per cent. of radium $\mathrm{C}$ is volatilized from a quartz surface after heating it for 5 minutes to $1320^{\circ}$, while from a nickel surface 99 per cent., and from a platinum surface 96 per cent., is volatilized at $1200^{\circ}$.

Such behaviour is easily explained if one takes into account the fact that volatilization necessitates the separation of the molecules of the active material from the molecules of the plate on which they are deposited. So the process is influenced not only by the vibrations and molecular attraction of the volatilizing substance, but also by the corresponding forces of the molecules composing the surface from which the volatilization takes place. A further acceleration of the process may be produced by the gases and vapours, especially water, which rapidly condenses on every solid surface on which the active material may be deposited. The fact that the volatility varies if the surface in question is heated very strongly can be explained by these considerations. It is improbable that there exists an action between the different radioactive atoms themselves, for in the experiments * v. Heresy, Phil. Mag. xxiii. p. 628 (1912).

$\dagger$ Makower, Manchester Memoirs, liii. No. 7 (1909). 
described later the mean distance between two atoms of the material deposited on a platinum wire is about 10,000 times as large as their radii.

\section{Volatilization of Actinium $B$.}

According to the work of Levin *, actinium $B$ is nonvolatile below $400^{\circ}$ but is completely volatilized at $750^{\circ}$ in about 10 minutes from a surface of platinum. In the present paper this subject has been examined in greater detail. It has been found impossible to get perfect agreement in different experiments, but results have been obtained sufficiently definite to test whether any considerable change in volatility could be effected by chemical treatment of the active substance.

Experimental details.-A platinum wire $0.13 \mathrm{~mm}$. thick, $10 \mathrm{~cm}$. long, was bent into a loop the ends of which were welded to two thick platinum wires. The latter were soldered to copper rods fitting into two brass rods $\mathrm{C}$, which were connected to the terminals of a hattery. By means of

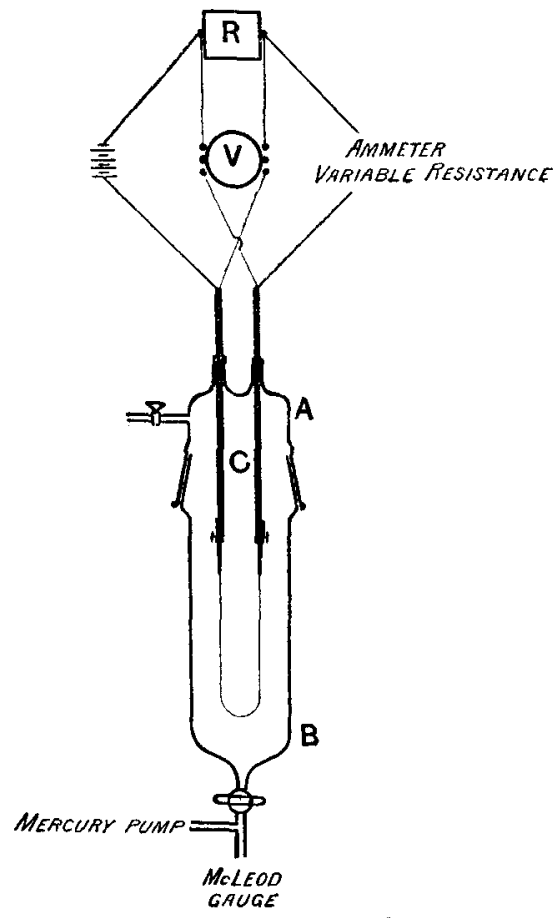

screws perfect contact was ensured. The disposition is shown in the figure. The temperature of the wire was found by comparing the fall of potential along the wire with that

* M. Levin, Phys. Zeitschr. rol. rii. p. 812 (1906). 
along a constant resistance $R(1.48 \mathrm{ohm})$ connected in series with the wire. The resistance of the wire was determined at $0^{\circ}, 100^{\circ}$, and $443^{\circ}$. From these data the temperature of the wire was calculated according to Callendar's formula. The melting-point of some particles of pure sodium sulphate, which were heated on the wire in vacuo, was observed by means of a microscope, and found to be $895^{\circ}$. This was considered a sufficient test for the accuracy of measurements at high temperatures.

Betore rendering the wire active, it was heated in vacuo for several minutes at $960^{\circ}$. It was then exposed to the emanation from an actinium preparation for 2 minutes. After 20 minutes, which is sufficient for actinium B, C, and $\mathrm{D}$ to obtain transient radioactive equilibrium, the activity of the wire was carefully determined in an $\alpha$-ray electroscope. The amount of the activity was usually about 80 divisions per minute.

The wire was then inserted in the vessel $A B$, and heated at a constant temperature for several minutes at a very low pressure. The amount of active material volatilized was given by the difference in activities of the wire before and after heating, a correction being made for the decay of activity during the time which had elapsed between the two measurements.

Volatilization of Actinium $B$ in vacuo.-The following are the results of experiments on the volatility of actinium $B$ at different temperatures, at a pressure of $.003 \mathrm{~mm}$. of air. 'The duration of heating was four minutes in all these experiments.

\begin{tabular}{|c|c|}
\hline Temperature. & Per cent. of actinium B volatilized. \\
\hline $600^{\circ}$ & Volatilization commences. \\
$700^{\circ}$ & 10 to 20 \\
$800^{\circ}$ & 30 to 50 \\
$900^{\circ}$ & 90 to 98 \\
\hline
\end{tabular}

Complete volatilization can only be effected at considerably higher temperatures. While the wire was being heated, the pressure in the vessel increased somewhat owing to the presence of the gas given off by the platinum. Special experiments showed, however, that this increase of pressure caused only a slight diminution in the amount volatilized at any temperature.

Pressures greater than $0 \cdot 1 \mathrm{~mm}$. were not used, since then 
the temperature of the wire could not be kept uniform owing to convection currents. The time during which the wire was heated naturally affected the amount of actinium $B$ volatilized. If the wire were heated for 1 minute instead of 4 minutes at $900^{\circ}$ only from 60 to 70 per cent. was removed.

Chemical Treatment of the Active Material.-In the following experiments, the active platinum wire was exposed for 10 to 15 minutes to gases and vapours which were thought c:lpable of acting chemically on the active material. Hydrochloric, hydrobromic, hydriodic acids, bromine, and chlorine were used for this purpose. The gases were dried by sulphuric acid. Bromine, pure, from Kahlbaum, was used directly. The action of hydrochloric acid gas on the active material did not affect its volatility. Bromine, however, produced an increase in the amount volatilized at a given temperature. For instance, after treatment with bromine, the wire was heated for 4 minutes to $675^{\circ}$ at a pressure of $.004 \mathrm{~mm} ., 77$ per cent. of actininm $B$ was rolatilized. From a wire not treated with bromine, on the other hand, only 18 per cent. volatilized under the same conditions of temperature and pressure.

It might appear possible that this increase in volatility is due to the action of the bromine on the platinum. Similar experiments in which quartz surfaces were used instend of platinum decided against this view. The experiments with quartz surfaces were conducted at atmospheric pressure in an ordinary electric furnace.

The following table shows some of the results:-

\begin{tabular}{|c|c|c|c|c|}
\hline \multicolumn{3}{|c|}{ Not treated. } & \multicolumn{2}{|c|}{ Treated with bromine. } \\
\hline Surface. & Temp. & $\begin{array}{l}\text { Per cent. } \\
\text { volatilized. }\end{array}$ & Temp. & $\begin{array}{l}\text { Per cent. } \\
\text { rolatilized. }\end{array}$ \\
\hline \multirow[t]{4}{*}{ Quartz. } & $650^{\circ}$ & 24 & $660^{\circ}$ & 78 \\
\hline & $655^{\circ}$ & 14 & $735^{\circ}$ & 82 \\
\hline & $670^{\circ}$ & 55 & & \\
\hline & $890^{\circ}$ & 75 & & \\
\hline \multirow[t]{2}{*}{ Platinum. } & $660^{\circ}$ & 0 & $670^{\circ}$ & 69 \\
\hline & $680^{\circ}$ & 2 & & \\
\hline
\end{tabular}

It is seen that bromine has the effect of increasing the Phil. Mag. S. 6. Vol. 24. No. 139. July 1912. K 
volatility of radium $B$. The figures also show the influence of the surface on the volatility.

Chlorine and hydriodic acid also increased considerably the volatility both of actinium B and of actinium C. From a quartz surface after treatment with hydriodic acid, actinium $\mathrm{C}$ volatilizes at a lower temperature than actinium B. At $560^{\circ}$, heating for two minutes caused about 40 per cent. of actinium $Q$ to volatilize, but only 13 per cent. of actinium $B$. No more experiments were made, however, in this direction, since it could hardly be hoped that they would decide whether the change in volatility was due to a change in the active material itself, or in the surface only. It is possible that a very thin layer of water of thickness about $10^{-6} \mathrm{~mm}$. which absorbs the gaseous acids may have a considerable influence.

In support of this assumption it may be added that, after treatment with gaseous hydrochloric acid, actinium B is more easily dissolved off a platinum surface by water than before such treatment. This is shown by the following experiments :-A strip of platinum was cleaned by placing it for a short time in boiling aqua regia. It was then heated in the blowpipe flame, and on cooling was boiled in a solution of ammonia. After it was heated again, it was exposed to actinium emanation for one minute. It was then kept in a slow current of gaseous hydrochloric acid for twenty minutes. Its activity was measured in an electroscope. The plate was then immersed in water for one minute and moved uniformly in it. It was dried with filter-paper, and the variation of its $\alpha$-ray activity observed for the next twenty minutes.

T'wo experiments were carried out exactly similar to these two, except that the active material was not kept in an atmosphere of hydrochloric acid after exposure to the emanation, but kept in a desiccator for twenty minutes. One series of results obtained is as follows :-

\begin{tabular}{|c|c|}
\hline $\begin{array}{l}\text { Methon of prerions } \\
\text { treatment. }\end{array}$ & $\begin{array}{l}\text { Percentnge loss of } \\
\text { actinium } B \text { slue to } \\
\text { immersion in water } \\
\text { during one minute. }\end{array}$ \\
\hline 1. Not treated with acid ............ & 24 \\
\hline 2. Jo. & 35 \\
\hline $\begin{array}{r}\text { 1. Treated with } \mathrm{HCl} \text { which was } \\
\text { dried with } \mathrm{H}_{2} \mathrm{SO}_{4}\end{array}$ & 82 \\
\hline $\begin{array}{l}\text { 2. Treated with } \mathrm{HCl} \text { which was } \\
\text { dried with } \mathrm{P}_{2} \mathrm{O}_{3} \ldots \ldots \ldots \ldots \ldots \ldots . . . . . .\end{array}$ & 81 \\
\hline
\end{tabular}


The decay-curves obtained showed that the loss of nctivity was due almost entirely to solution of actinium $B$ in the water. Only a very small quantity, if any, of actinium $\mathrm{C}$ was dissolved. The platinum surface had not suffered any visible change by this treatment. It appears, however, that a thin layer of acid is formed on the surface of the metal by the treatment, becanse the activity can be relatively easily removed from such a piece by rubbing. Incidentally it may be mentioned that actinium $B$ is easily dissolved by acids even in very dilute solution. A concentration of $\cdot 001$ normal hydrochloric or sulphuric acid is sufficient to dissolve in a minute more than 95 per cent. of the actinium $\mathrm{B}$ off a quartz surface, and more than 80 per cent. off a platinum one. Hardly any actinium $\mathrm{C}$ is, however, removed by this treatment.

It is obvious from the experiments described that the nature of the surface and of the surface-layer is an important but indefinite factor in the volatilization of minute quantities. For this reason experiments were made along a different line in which this factor is partly eliminated.

\section{Condensation Eaperiments.}

In the experiments which will now be described, the active material was fret volatilized completely and the amount and composition of the material condensed on surfaces at definite temperatures investigated. It is to be expected that the active material would begin to condense as soon as it reaches a surface whose temperature is less than the volatilization-temperature. By this method volatility can be measured independent of any effect due to the surface-layer, since the condensation lakes place at high temperatures.

The experimental arrangement was as follows:-The porcelain tube of an electric furnace placed vertically upright was closed at its lower end by asbestos and kieselguhr. Inside this was placed a quartz tube $32 \mathrm{~cm}$. long and $1 \cdot 1 \mathrm{~cm}$. wide, closed at its lower end. The furnace was wound with a platinum wire in such a way that the temperature was highest at its lowest point and gradually decreased towards the other end. The active material was volatilized from a platinum surface, and was condensed on a thin long mica strip placed inside the quartz tube. The temperature of this strip at different points was determined by means of a thermocouple.

As soon as the furnace had reached a steady state of temperature, a small piece of very active platinum wire was 
dropped into the quartz tube. The temperature at the bottom of the tube was usually higher than $900^{\circ}$, so that the greater part of the material volatilized and was deposited again on the cooler parts of the tube and on the mica. After some minutes the latter was removed and cut into parts of equal lengths which were measured on both sides in an a-ray electroscope.

Experiments were conducted in air and in hydrogen. In experiments with the latter the tube was filled first with carbon dioxide and then with hydrogen. By means of a special device the active wire was dropped into the tube without opening it. The interval of time which was allowed to elapse between inserting the wire and removing the mica varied from 5 to 15 minutes in different experiments.

Volatility in Arr.-The experiments showed the unexpected result that actinium $B$, after volatilization in air, becomes much less volatile than it had been when the experiments were conducted in vacuo. The details of one experiment are given in the following table:-

Interval of time between insertion of the active wire and removal of the mica, 5 minutes.

\begin{tabular}{|c|c|c|}
\hline Length No. & Temperature. & $\begin{array}{c}\text { Activity } \\
\text { in div. per min. }\end{array}$ \\
\hline $0 \quad \ldots \ldots$ & Greater than $1090^{\circ}$ & 1200 \\
\hline $1 \ldots$. & $1075^{\circ}$ to $1090^{\circ}$ & 100 \\
\hline $2 \ldots$ & $1045^{\circ}$ to $1075^{\circ}$ & 2 \\
\hline $3, \& \mathrm{c}, \ldots \ldots \ldots \ldots$ & less than $1045^{\circ}$ & 0 \\
\hline
\end{tabular}

When a platinum strip was used instead of a mica one, an appreciable amount of activity was obtained above $1000^{\circ}$.

It thus follows that all the volatilized actinium $B$ is deposited in air at temperatures above $1000^{\circ}$, although it begins to volatilize from a surface at $600^{\circ}$. Experiments with thorium $B$ and $C$ give the same results. A. S. Russell has carried ouc experiments for radium $\mathrm{C}$ and has shown that its behaviour is similar.

Volatility in Hydrogen.-The distribution of activity along the mica strip was found to be entirely different when the volatilization was carried out in an atmosphere of hydrogen. In contrast to the experiments with air the activity condensed on cooler parts of the mica, the maximum amount of 
actinium $B$ being deposited between $615^{\circ}$ and $675^{\circ}$. This is shown clearly in the following table :-

Interval of time between insertion of the active wire and removal of the mica, 15 minutes.

\begin{tabular}{|c|c|c|}
\hline Length No. & 'Temperature. & $\begin{array}{c}\text { Activity } \\
\text { in div. per min. }\end{array}$ \\
\hline $0 \quad \ldots \ldots \ldots$ & Greater than $960^{\circ}$ & 8 \\
\hline $1 \quad \ldots \ldots \ldots \ldots$ & $945^{\circ}-960^{\circ}$ & 8 \\
\hline $2 \quad \ldots \ldots \ldots \ldots$ & $925^{\circ}-945^{\circ}$ & 9 \\
\hline $3 \quad \ldots \ldots \ldots \ldots$ & $880^{\circ}-925^{\circ}$ & 5 \\
\hline $4 \quad \ldots \ldots \ldots \ldots$ & $820^{\circ}-880^{\circ}$ & 3 \\
\hline $5 \quad \ldots \ldots \ldots \ldots$ & $760^{\circ}-820^{\circ}$ & 4 \\
\hline $6 \quad \ldots \ldots$ & $675^{\circ}-760^{\circ}$ & 84 \\
\hline Half of $7 \ldots$. & $615^{\circ}-675^{\circ}$ & 780 \\
\hline Half of $7 \ldots$. & $555^{\circ}-615^{\circ}$ & 5 \\
\hline $8 \quad \ldots \ldots \ldots \ldots$ & $385^{\circ}-555^{\circ}$ & 10 \\
\hline $9-11 \ldots \ldots \ldots$. & $200^{\circ}-385^{\circ}$ & 5 \\
\hline
\end{tabular}

Similar results were obtained with thorium $B$ and $C$. Since the decay of thorium $C$ is much slower than that of the corresponding member of the actiniun series, it was possible to determine the ratio of the amounts of $B$ and $C$ deposited at different temperatures. Thorium $B$ was deposited almost pure on the hotter parts of the strip, thorium $\mathrm{C}$ on the cooler. The latter product is consequently more volatile in hydrogen than the former. Further experiments on this point are in progress.

\section{Conclusion.}

It has been shown that the radioactive matter when once volatilized condenses on a surface at a much lower temperature in an atmosphere of hydrogen than in an atmosphere of air. This suggests that the active matter forms compounds in the presence of air which are less volatile and consequently easier to condense than the reduction products obtained in hydrogen, which are perhaps the elements, $i . e$. the metals themselves. The assumption is in agreement with the behaviour of common metals and their oxides, the former being generally more volatile than the latter.

The fact that the volatilization of actinium B from platinum, as shown above, takes place over a long range of 
temperature may be due to a partial oxidation of the active substance. Moreover, the very great volatility of the active deposit of radium in sealed quartz tubes observed by Russell *, as contrasted with the results of Makower + , is due to the fact that the former bad hydrogen in his tubes. This point is treated by Mr. Russell in the following paper.

\section{Summary.}

1. The volatilization of actinium B deposited on platinum has been measured in a high vacuum and has been found to take place between $600^{\circ}$ and $900^{\circ}$.

2. By allowing chlorine, bromine, hydrobromic acid, and hydriodic acid to act on the active material its volatility can be increased.

3. The $B$ and $C$ products of the active deposits of radium, thorium, and actinium condense in an atmosphere of hydrogen at a temperature several hundred degrees lower than in air. This has been explained by the formation of chemical compounds.

I wish to express my sincerest thanks to Prof. Rutherford for suggesting these experiments and for his ever ready advice and help.

Physical Laboratories,

University, Manchester.

X. The Volatility of Radium C $\ddagger$ : By ÁLexANder S. Russeld, Carnegie Research Fellow of the University of Glasgow.

THE interesting results described by Dr. Schrader in the 1 foregoing paper show clearly that the constituent elements of the radioactive deposits are capable of forming chemical compounds. Dr. Schrader deals with the active deposits of thorium and actinium. In this paper, which is merely an appendix to his, the volatility of the radium active deposit is discussed.

Makower $\S$ has shown that radium A, radium B, and radium $C$ cannot remain on a platinum surface when it is heated in air to temperatures of $900^{\circ}, 600^{\circ}$, and $1200^{\circ}$ respectively. From a quartz surface the least volatile product of

* Russell, Proc. Roy. Soc. A. vol. 1xxxvi. p. 276 (1912).

+ Makower, loc. cit.

$\$$ Communicated by Prof. E. Rutherford, F.R.S.

W. Makower, Manchester Memoirs, liii. No. 7 (1909). 